University of Nebraska - Lincoln

DigitalCommons@University of Nebraska - Lincoln

3-1-1992

\title{
Temperature Oscillations of Alternating-Current-Heated Thin Filaments in Ceramic Fiber Production
}

Hendrik J. Viljoen

University of Nebraska-Lincoln, hviljoen1@unl.edu

Vladimir Hlavacek

Laboratory for ceramic and Reaction Engineering, Department of chemical Engineering, State University of New York at Buffalo, Amherst, New York-14260

Follow this and additional works at: https://digitalcommons.unl.edu/chemengreaction

Part of the Chemical Engineering Commons

Viljoen, Hendrik J. and Hlavacek, Vladimir, "Temperature Oscillations of Alternating-Current-Heated Thin Filaments in Ceramic Fiber Production" (1992). Papers in Reaction Kinetics. 7.

https://digitalcommons.unl.edu/chemengreaction/7

This Article is brought to you for free and open access by the Chemical and Biomolecular Engineering Research and Publications at DigitalCommons@University of Nebraska - Lincoln. It has been accepted for inclusion in Papers in Reaction Kinetics by an authorized administrator of DigitalCommons@University of Nebraska - Lincoln. 


\title{
Temperature Oscillations of Alternating-Current-Heated Thin Filaments in Ceramic Fiber Production
}

\author{
Hendrik J. Viljoen* \\ Department of Chemical Engineering, University of Nebraska-Lincoln, Lincoln, Nebraska $68588-0126$ \\ Vladimir Hlavacek*
}

Laboratory for Ceramic and Reaction Engineering, Department of Chemical Engineering, State University of New York at Buffalo, Amherst, New York 14260

\begin{abstract}
Resistively heated filaments are used to manufacture ceramic fibers. When an ac power source is used for heating, the temperature of the filanent oscillates. These oscillations influence the deposition rate on the surface of the filament. An analysis of this problem is presented, and it is also shown that these oscillatory effects diminish as the filament gauge increases. The analysis can help to decide whether an ac or a dc power source should be used. [Key words: resistivity, heating, filaments, temperature, oscillations.]
\end{abstract}

\section{Introduction}

$\mathbf{F}$ OR the manufacture of some ceramic fibers, a thin filament is mounted between two electrodes inside a cylindrical reactor (c.g., quartz tube), or in the case of continuous fiber production, the filament is pulled through a set of conducting seals. In batch reactors the filament is mounted in a tensilc state, and in continuous reactors the pulling action through the scals applies a tensile load on the filament. The filament is resistively heated to 1150 to $1350 \mathrm{~K}$, and a gascous mixture containing the reactive precursors flows axially along the fiber and reacts on the fiber surface to form a protective ceramic coating. ${ }^{\prime}$

During experiments conducted in the Laboratory for Ceramic and Reaction Engineering with tungsten filaments, it was observed that the filament underwent oscillations when an ac source was used. In some cases, the oscillations changed in anplitude and wave number during the course of the reaction. These observations prompted our investigation into the matter. Our analysis indicates that the vibration of the filament is caused by thermal stresses in the filament. The ac source causes oscillating filament temperatures, and the alternating thermal expansion leads to periodic changes in the axial tensile stress of the filament. The thermal stresses are superimposed on the applied tensile stress in the filament and will influence the final strength of the filament. A better understanding of these effects is important, because the final strength of the fiber depends on the stresses which are present during the manufacturing stage.

Apart from the disastrous effect that the vibrating filament has on the deposited film's quality, temperature oscillations also lead to oscillations in the deposition rate. However, the analysis shows that the amplitude of the temperature oscillations decrease with the cube of the filament diameter and these oscillatory effects become small when the filament gauge increases. Therefore, under certain conditions it may be possible and nore cconomical to use ac rather than de hoaling.

J.J. Cnid-combiroting, editor

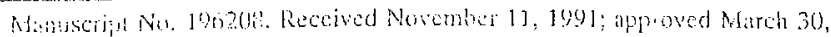
$10 ! 3 !$

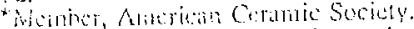

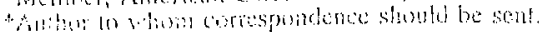

Thin filaments which are electrically heated are also used in other technologies. Examples of these applications are found in the catalytic oxidation of hydrocarbons on $\mathrm{Pt}$ wire ${ }^{2}$ and the deposition of diamond films by the hot-filament technique. ${ }^{3}$ It is the purpose of this note to communicate some of our cxperiences with ac heating of thin filaments and to report the results of our analysis.

\section{Results and Discussion}

Only the results will be discussed and interested readers are referred to a more detailed analysis. ${ }^{4}$ In Figs. 1 and 2 the temperature of a 100 and $10 \mu \mathrm{m}$ tungsten filament, respectively, are shown as functions of timc. The temperatures were calculated for the position midway between the mounting blocks, which are $30 \mathrm{~cm}$ apart. The filaments were heated to a mean temperature of $1200 \mathrm{~K}$ in both cases, using a $50 \mathrm{~Hz}$ ac source. The heat transfer coefficient was taken as $U=250 \mathrm{~W} / \mathrm{m}^{2} \cdot \mathrm{K}$. One immediately notes that the amplitude of the oscillations increased from $\approx 30$ to $300 \mathrm{~K}$ as the diameter of the filament decreased from 100 to $10 \mu \mathrm{m}$. The maxinum anplitude of the temperalure oscillation is described by the following:

$$
\Delta T_{\max }=\frac{16 I^{2} \rho_{\mathrm{R}}}{\pi^{2} D^{3} U} \frac{\left\{\cos \left[\tan ^{-1}\left(\frac{2}{a}\right)\right]+\frac{2}{a} \sin \left[\tan ^{-1}\left(\frac{2}{a}\right)\right]\right\}}{\left(1+\frac{4}{a^{2}}\right)}
$$

where $I$ is the current (in amperes), $\rho_{\mathrm{R}}$ is the resistivity, $D$ is the filament diameter, $U$ is the heat transfer cocfficient, and $a$ is a dimensionless parameter $\left(a=4 U / D \omega \rho C_{p}\right)$. The frequency

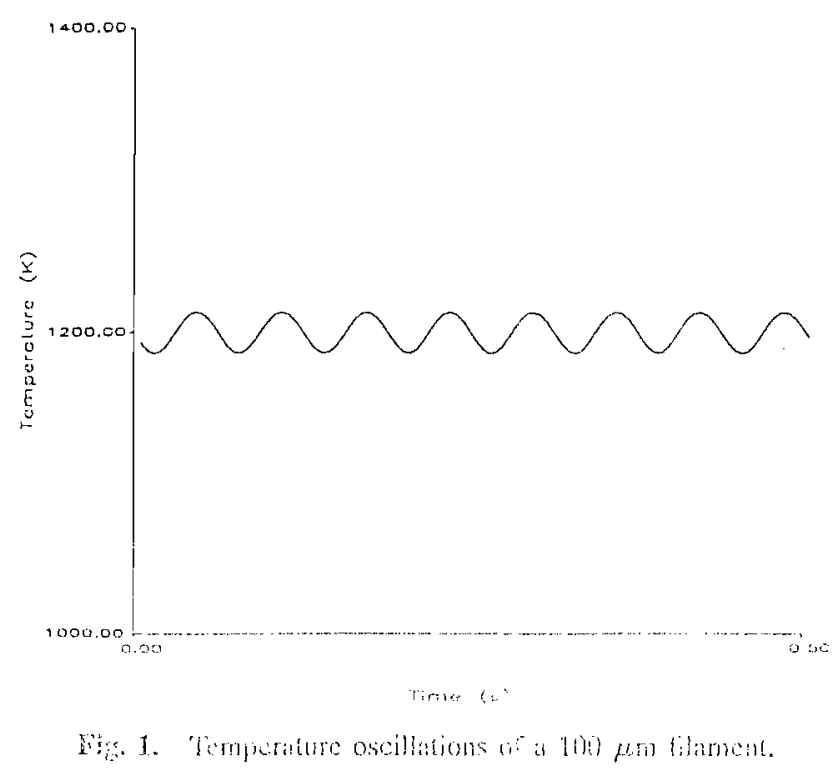




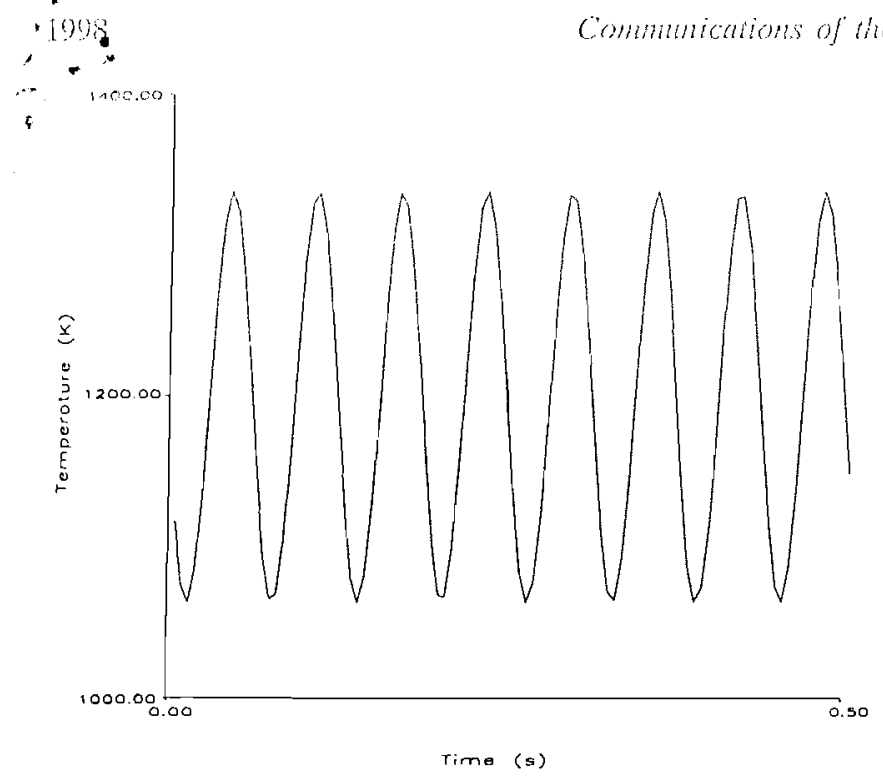

Fig. 2. Temperature oscillations of a $10 \mu \mathrm{m}$ filament.

of the ac source is $\omega$, and the density and specific heat capacity of the filament are $\rho$ and $C_{p}$, respectivcly. Equation (1) gives a simple relation between physical conditions and the maximum amplitude of the temperature oscillation. Any temperature-dependent process on the surface of the filament (e.g., deposition, thermoionic emission, or a catalytic reaction) will also oscillate, and the magnitude of this oscillation can now be casily established.

To illustrate the effect that this oscillating temperature will have on the deposition process, consider the coating of tungsten fibers by boron ( $\mathrm{BCl}_{3}$ and $\mathrm{H}_{2}$ as precursors). Details of the process and the kinctics in particular were published elscwherc. ${ }^{1}$ The rate of boron deposition is described by the following cquation:

$$
R_{\mathrm{B}}=17 \mathrm{e}^{-15600 \mathrm{r}}\left[f_{1}-f_{2}\right] \frac{\mathrm{kmol}}{\mathrm{m}^{2} \cdot \mathrm{s} \cdot \mathrm{kPa}}
$$

where $f_{1}$ and $f_{2}$ denote forward and backward reaction rates, respectivcly:

$$
\begin{aligned}
& f_{1}=\frac{K_{\mathrm{eq}}^{1} \chi_{\mathrm{BC} l_{3}} \chi_{\mathrm{H}_{2}}}{\chi_{\mathrm{HCl}}\left[1 / p-K_{\mathrm{HCl}} \chi_{\mathrm{HCl}}\right]} \\
& f_{2}=\frac{\chi_{\mathrm{HCl}}^{2}}{K_{\mathrm{eq}}^{2} \chi_{\mathrm{H}_{2}}\left[1 / p+K_{\mathrm{HCl}} \chi_{\mathrm{HCl}}\right]}
\end{aligned}
$$

For illustrative purposes, we will consider average values for all molar fractions as $\chi_{\mathrm{BCl}_{3}}=0.05, \chi_{\mathrm{H}_{2}}=0.949$, and $\chi_{\mathrm{HCl}}=0.001$. Then the following relationship results:

$$
\begin{aligned}
& R_{\mathrm{B}}=17 \mathrm{e}^{-15600 / T}\left[\chi_{\mathrm{BCl}_{3} \chi_{\mathrm{H}_{2}}} \frac{\mathrm{e}^{2-5640 / T-6.8 \times 10^{8} / T^{3}}}{\chi_{\mathrm{HCl}}\left(0.01-0.0249 \chi_{\mathrm{HCl}} \mathrm{e}^{4982 / T}\right)}\right. \\
& \left.-\frac{\chi_{\mathrm{HCl}}^{2}}{\chi_{\mathrm{H}_{2}} \mathrm{e}^{(.37 \exp (0.0069 T)-3321) / T}\left(0.01+0.0249 \chi_{\mathrm{HCl}} \mathrm{e}^{4982 / T}\right)}\right]
\end{aligned}
$$

Using the oscillating temperature shown in Fig. 2 , the relative rate can be calculated and it is shown in Fig. 3. The relative rate is defined as $R_{\mathrm{B}}(T) / R_{\mathrm{B}}(1200)$, where the mean temperature is $1200 \mathrm{~K}$. The rate has a maximum of 6.3 times the value of $R_{\mathrm{B}}(1200)$ and decreases to $1 / 10$ of this value. Note that the ime scale in the figure presents real time. The period of the scillations in all cases, is $1 / 16$ of a second (i.e., $2 \pi / 100$ ). This example illustrates the effect of the ac source on the deposition rate. But the temperature oscillations also affect the final strength of the fiber.

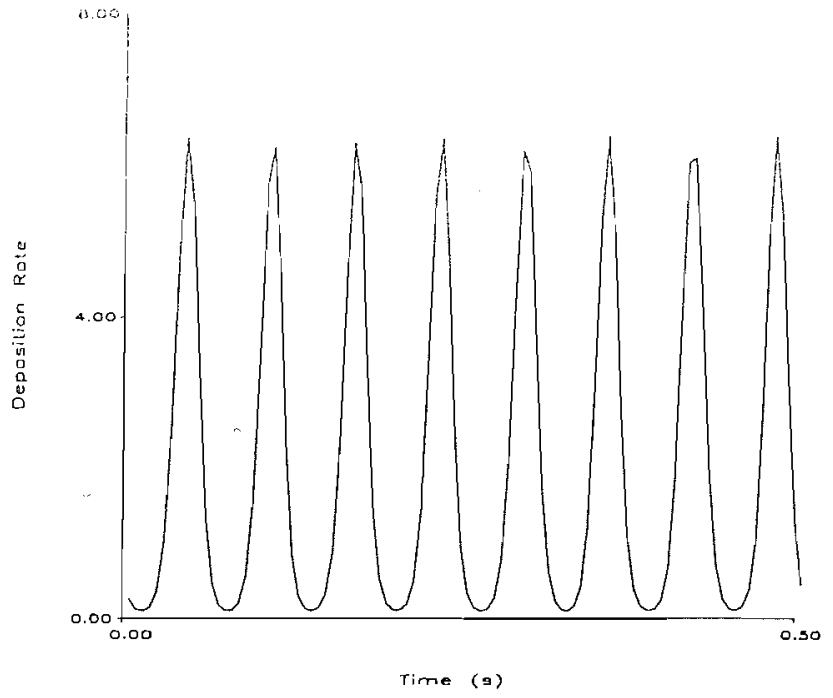

Fig. 3. Oscillations in reaction rate on a $10 \mu \mathrm{m}$ filament.

If the filament is mounted so at all times a net tension is maintained, the filament can potentially start to vibrate. In practice, the filament is tightened between the electrodes before the current is switched on. After the required temperature is reached, the filament is usually slack and it is tightened again before deposition is started. The second tightening puts a tension on the filament and if any vibrations are observed, the tension is further increased. This arbitrary tightening of the filament can be avoided, if onc analyzes the stability of the governing equation and understands the underlying mechanism. It is important to know the tensilc load during deposition, because it will affect the final strength of the ceramic fiber. To maintain a net tension in the filament, the tension used in its mounting will vary between two limits as described by the following equation:

$$
P>\sigma>\sigma_{\min }=\frac{\gamma\left\{\cos \left[\tan ^{-1}\left(\frac{2}{a}\right)\right]+\frac{2}{a} \sin \left[\tan ^{-1}\left(\frac{2}{a}\right)\right]\right\}}{2 a\left(1+\frac{4}{a^{2}}\right)}
$$

where $P$ is the maximum tensile strength. The parameter $\gamma$ is defined as $\gamma=E_{Y} \alpha I^{2} \rho_{\mathrm{R}} / A^{2} \omega \rho C_{\mathrm{p}}$ where $E_{Y}$ is the Young's modulus, $\alpha$ is the thermal expansion coefficient, and $A$ is the cross-sectional area of the filament. $\sigma_{\min }$ is also the lower bound on the applied tensile stress, and the right-hand side of Eq. (3) gives the minimum applied tension on the filament during the manufacturing stage.

In more general terms, this analysis can be used for any acheated thin-filament technology, provided that the temperature dependence of the process under consideration is known. An example is the deposition rate expression (Eq. (2)) which can be used together with Eq. (1) to determine the magnitude of the oscillations in the deposition rate. Alternating-current heating can be considered for a process, if the effects of the oscillations are sufficiently small.

\section{References}

'J.H. Scholtz, H.J. Viljoen, J.E. Gatica, and V. Hlavacek, "Coating of Fibrous Substrates by CVD; Analysis of the Fiber Evolution," J. Cryst. Growth, 108, 190-202 (1991).

${ }^{2}$ G. Philippou, F. Schultz, and D. Luss, "Spatiotemporal Temperature Patterns on an Electrically Heated Catalytic Ribbon," J. Phys. Chem., 95 [8] 3224-29 (1991).

${ }^{3}$ F. Jansen, M.A. Machonkin, and D.E. Kuhman, "The Deposition of Diamond Films by Filamenl Techniques,"J. Vac. Sci. Technol., A, 8 [5] 3785-90 (1990).

${ }^{4}$ H. J. Viljoen and V. Hlavacek, "Temperature Oscillations and Vibrations of AC-Resistively Heated Thin Filaments," A/ChE J., 38 [2] 284-90 (1992). $\square$ 